\title{
Small incision lenticule extraction (SMILE) techniques: patient selection and perspectives
}

This article was published in the following Dove Press journal:

Clinical Ophthalmology

\author{
Jeewan S Titiyal \\ Manpreet Kaur \\ Farin Shaikh \\ Meghal Gagrani \\ Anand Singh Brar \\ Anubha Rathi
}

Cornea, Cataract and Refractive Surgery Services, Dr Rajendra Prasad Centre for Ophthalmic Sciences, All India Institute of Medical Sciences, New Delhi, India
Correspondence: Jeewan S Titiyal

Cornea, Cataract and Refractive Surgery Services, Dr Rajendra Prasad Centre for Ophthalmic Sciences, All India Institute of Medical Sciences, Ansari Nagar, New Delhi I I0029, India

Tel +9l II 26593 I 46

Email titiyal@gmail.com

\begin{abstract}
Refractive lenticule extraction is becoming the procedure of choice for the management of myopia and myopic astigmatism owing to its precision, biomechanical stability, and better ocular surface. It has similar safety, efficacy, and predictability as femtosecond laser-assisted in situ keratomileusis (FS-LASIK) and is associated with better patient satisfaction. The conventional technique of small incision lenticule extraction (SMILE) involves docking, femtosecond laser application, lenticule dissection from the surrounding stroma, and extraction. It has a steep learning curve compared to conventional flap-based corneal ablative procedures, and the surgical technique may be challenging especially for a novice surgeon. As SMILE is gaining worldwide acceptance among refractive surgeons, different modifications of the surgical technique have been described to ease the process of lenticule extraction and minimize complications. Good patient selection is essential to ensure optimal patient satisfaction, and novice surgeons should avoid cases with low myopia (thin refractive lenticules), difficult orbital anatomy, high astigmatism, or uncooperative, anxious patients to minimize complications. A comprehensive MEDLINE search was performed using "small incision lenticule extraction," "SMILE," and "refractive lenticule extraction" as keywords, and we herein review the patient selection for SMILE and various surgical techniques of SMILE with their pros and cons. With increasing surgeon experience, a standard technique is expected to evolve that may be performed in all types of cases with optimal outcomes and minimal adverse effects.
\end{abstract}

Keywords: refractive lenticule extraction, femtosecond-laser assisted lenticule extraction, SMILE techniques, refractive surgery

\section{Introduction}

Refractive lenticule extraction marks a paradigm shift in the field of refractive surgery from the conventional flap-based corneal ablative procedures to flap-less extraction of femtosecond laser-created intrastromal lenticules. Sekundo et al described the extraction of an intrastromal lenticule after lifting a flap in 2008, and the technique evolved to the present-day small incision lenticule extraction (SMILE), wherein the refractive lenticule is extracted through a small 2- to 5-mm side cut incision. ${ }^{1-3}$ At present, the VisuMax Laser System (Carl Zeiss Meditec AG, Jena, Germany) is the only laser platform approved for the creation of an intrastromal refractive lenticule. ${ }^{4}$

SMILE is comparable to femtosecond laser-assisted in situ keratomileusis (FSLASIK) in terms of safety, efficacy, and predictability. ${ }^{5,6}$ Moreover, it has the advantages of better ocular surface stability and biomechanical strength compared to FS-LASIK. ${ }^{6-10}$ It provides precise visual acuity and quality and is increasingly being preferred for the treatment of myopia and myopic astigmatism owing to the enhanced patient satisfaction.

However, the steep learning curve of SMILE may prove to be challenging especially for beginners. ${ }^{11,12}$ A stepwise approach consisting of observation, initial wetlab 
training, and flap-based refractive lenticule extraction (femtosecond lenticule extraction [FLEx] and pseudo-SMILE) may help to familiarize the novice surgeon with lamellar separation and handling the refractive lenticule. ${ }^{1,11,13} \mathrm{~A}$ high incidence of intraoperative complications may be observed during the initial learning phase, and the majority of these are a result of difficult lenticule dissection and extraction. . $^{11,14,15}$ As SMILE is gaining worldwide acceptance among refractive surgeons, different modifications of the surgical technique have been described to ease the process of lenticule extraction and minimize complications. We herein review the various surgical techniques of SMILE with their pros and cons and the perspectives involved in patient selection.

A comprehensive MEDLINE search was performed using "small incision lenticule extraction," "SMILE," and "refractive lenticule extraction" as keywords, and all articles pertaining to patient selection and techniques of SMILE were reviewed.

\section{Patient selection for SMILE}

SMILE received US Food and Drug Administration (FDA) approval in 2016 for the treatment of myopia from $-1 \mathrm{D}$ to $-8 \mathrm{D}$ and astigmatism up to $-0.5 \mathrm{D}$, with a manifest refraction spherical equivalent (MRSE) of less than or equal to $-8.25 \mathrm{D}$ in patients aged 22 years or older. ${ }^{16}$ It has received Conformité Européene approval for the correction of MRSE up to $-11.5 \mathrm{D}$, including $-10 \mathrm{D}$ of myopia and $-3 \mathrm{D}$ of myopic astigmatism.

The pre-operative assessment and patient selection in SMILE is similar to that of flap-based refractive surgeries. The presence of abnormal topography and forme fruste keratoconus must be ruled out. For SMILE, the percentage tissue altered (PTA) is calculated as (lenticule thickness + cap thickness)/central corneal thickness, and a value of more than $40 \%$ is suggestive of an increased risk of ectasia. ${ }^{17}$

\section{Ocular surface}

SMILE has superior ocular surface stability compared to flap-based refractive surgeries. The sub-basal nerve fiber regeneration is faster, and dry eye symptoms, if present, are milder and recover faster. ${ }^{6-9}$ The enhanced ocular surface stability makes SMILE a more feasible option for cases with pre-existing mild dry eyes.

\section{Corneal biomechanics}

SMILE involves the creation of a small side cut as opposed to a circumferential flap in laser-assisted in situ keratomileusis (LASIK). The biomechanical strength of the cornea is greater in its anterior layer due to stronger intralamellar collagen bonding, and SMILE results in minimal disruption of peripheral collagen fibers resulting in relatively better corneal biomechanics. ${ }^{18,19}$ Only a few case reports have observed post-SMILE ectasia, and it may be preferred over LASIK in cases with higher refractive errors. ${ }^{20-23}$

\section{Occupation}

The absence of a flap and related complications makes SMILE a viable option for patients involved in contact sports or at risk of flap dislodgement.

\section{Pupil size}

The induced higher order aberrations (HOAs) as well as spherical aberrations are less with SMILE. ${ }^{24-26}$ Patients with large pupils are prone to experience glares and halos after LASIK due to increased spherical aberrations, and SMILE may be preferred in such cases.

\section{Difficult anatomy}

Suction loss is more commonly observed after SMILE as it is a low-pressure system (about $35 \mathrm{mmHg}$ ) with longer suction time (25-28 seconds) compared to FS-LASIK. Patients with deep set eyes, patients with small palpebral fissures, or anxious or uncooperative patients are prone to develop suction loss and may be given the option of FSLASIK or photorefractive keratectomy (PRK).

\section{Learning curve}

SMILE has relatively steep learning curve and may be more challenging to perform than LASIK in the initial phase of learning for the operating surgeon.

\section{Contraindications}

The contraindications for SMILE are similar to those of other refractive surgeries (Table 1). Unstable refraction

Table I Absolute and relative contraindications for SMILE

\begin{tabular}{|c|c|}
\hline $\begin{array}{l}\text { Absolute contraindications to } \\
\text { SMILE }\end{array}$ & $\begin{array}{l}\text { Relative contraindications } \\
\text { to SMILE }\end{array}$ \\
\hline $\begin{array}{l}\text { Pre-existing corneal ectasia } \\
\text { (keratoconus, PMD) }\end{array}$ & Age $\leq 21$ years \\
\hline Unstable refractive error & $\begin{array}{l}\text { Mild/treated ocular surface } \\
\text { and tear film disorders }\end{array}$ \\
\hline Exposure keratopathy & $\begin{array}{l}\text { Epithelial and basement } \\
\text { membrane corneal dystrophies }\end{array}$ \\
\hline $\begin{array}{l}\text { Ocular surface and tear film disorders } \\
\text { such as active uncontrolled ocular } \\
\text { allergy, severe dry eye, blepharitis }\end{array}$ & Systemic immunodeficiency \\
\hline Pregnancy and breastfeeding & Controlled diabetes mellitus \\
\hline One-eyed patient & Past ocular herpes infection \\
\hline Uncontrolled glaucoma or uveitis & History of keloid formation \\
\hline
\end{tabular}

$\overline{\text { Abbreviations: PMD, pellucid marginal degeneration; SMILE, small incision lenticule }}$ extraction. 
with $\geq 0.5 \mathrm{D}$ change in the past 1 year is a contraindication for SMILE. SMILE should be avoided in the presence of ocular ectatic diseases like keratoconus and pellucid marginal degeneration, uncontrolled ocular allergic disease, active blepharitis, significant dry eye disease or other ocular surface diseases like epithelial basement membrane dystrophy, history of ocular herpes infection, and ocular comorbidities such as glaucoma, uveitis, retinal tears, or detachment.

\section{Patient selection for beginners}

The novice surgeon should avoid cases with low myopia as it may not be possible to delineate the lenticule edge in such thin lenticules thereby increasing the risk of inadvertent lenticule mis-dissection and cap lenticular adhesions. ${ }^{11}$ Moderate to high myopia of $4 \mathrm{D}$ or more results in a thicker lenticule, which is relatively easy to handle. Patients with difficult orbital anatomy such as deep set eyes, narrow palpebral aperture, and prominent nose are more prone to suction loss and should be avoided for the initial few cases. Uncooperative or extremely anxious patients with frequent ocular and head movements may be difficult to handle for beginners and should be avoided. Cases with high astigmatism wherein compensation for cyclotorsion is essential should be tackled only by experienced SMILE surgeons.

\section{Machine and laser settings}

The VisuMax Femtosecond Laser System (Carl Zeiss Meditech AG) delivers focused patterns of femtosecond pulses with a wavelength of $1,043 \mathrm{~nm}$ and frequency of $500 \mathrm{kHz}$ to create an intrastromal refractive lenticule at a precise pre-decided depth and position. The machine consists of a computer unit, laser arm and vacuum system, microscope, patient supporting system, and a foot switch. Different illumination systems are integrated in the machine, including diffuse, slit, and infrared illumination. The patient interface (PI) is a single-use disposable contact lens with attached tubing that provides the interface between the patient and the machine and is referred to as a treatment pack. It is available in three sizes - small, medium, and large (S, M, and L, respectively) based on the white-to-white diameter of the patient.

Laser settings are programmed in the machine and depend on the mode selected. Three modes of treatment are available, that is "standard", "fast", and "expert" modes (Table 2). ${ }^{4}$

- The standard mode has preset default laser settings programmed by the manufacturers.

- The laser settings in the fast mode may be altered only by the application specialists and are customized according to the region.

- The expert mode has modifiable laser settings, which may be optimized by the surgeon before each case as per the surgeon preference and patient response. The laser parameters of the fast mode may be modified within a certain range; however, it is advisable to consult the application specialist regarding the optimal laser and energy settings, especially in the initial learning phase.

The laser settings may be modified to set the spot distance, track distance, pulse energy, and energy offset. Spot spacing is the distance between two adjacent laser spots and ranges from 2.0 to $4.5 \mu \mathrm{m}$. Track spacing is the distance between two laser spots in adjacent tracks and ranges from 2.0 to $4.5 \mu \mathrm{m}$. Pulse energy defines the size of the cavitation bubbles, which are produced during femtosecond laser cuts. It lies in the range of 100-260 nJ (recommended 100-160 nJ). One energy offset is equivalent to $5 \mathrm{~nJ}$ of pulse energy and ranges from 20 to $52 \mathrm{~nJ}$ (recommended 20-32 nJ). Scan direction is conventionally spiral in for posterior plane and spiral out for anterior plane.

\section{Standard technique of SMILE}

The standard technique of SMILE involves docking, femtosecond laser application, lenticule dissection, and extraction. ${ }^{2,3,11}$ The refractive lenticule is separated from the surrounding stroma by blunt dissection via the small side-cut incision, first in the anterior plane followed by the posterior plane.

Table 2 Laser parameters set during SMILE in various treatment modes

\begin{tabular}{|c|c|c|c|}
\hline Laser parameter & Expert mode ${ }^{a}$ & Standard mode ${ }^{b}$ & Fast mode ${ }^{c}$ \\
\hline Pulse energy & I40-200 nJ & $130 \mathrm{~nJ}$ & I70 nJ \\
\hline Energy offset (l offset = $5 \mathrm{~nJ})$ & $28-40$ & 26 & 34 \\
\hline Track distance & $\begin{array}{l}\text { Lenticule and cap cuts: } 4.5 \pm 0.5 \mu \mathrm{m} \\
\text { Lenticule and cap side cuts: } 2 \pm 0.5 \mu \mathrm{m}\end{array}$ & $\begin{array}{l}\text { Lenticule and cap cuts: } 3 \mu \mathrm{m} \\
\text { Lenticule and cap side cuts: } 2 \mu \mathrm{m}\end{array}$ & $\begin{array}{l}\text { Lenticule and cap cuts: } 4.5 \mu \mathrm{m} \\
\text { Lenticule and cap side cuts: } 2 \mu \mathrm{m}\end{array}$ \\
\hline Spot distance & $\begin{array}{l}\text { Lenticule and cap cuts: } 4.5 \pm 0.5 \mu \mathrm{m} \\
\text { Lenticule and cap side cuts: } 2 \pm 0.5 \mu \mathrm{m}\end{array}$ & $\begin{array}{l}\text { Lenticule and cap cuts: } 3 \mu \mathrm{m} \\
\text { Lenticule and cap side cuts: } 2 \mu \mathrm{m}\end{array}$ & $\begin{array}{l}\text { Lenticule and cap cuts: } 4.5 \mu \mathrm{m} \\
\text { Lenticule and cap side cuts: } 2 \mu \mathrm{m}\end{array}$ \\
\hline
\end{tabular}

Notes: aThe expert mode allows the surgeon to vary the "fast" mode settings within a certain range. ${ }^{\mathrm{b}}$ The standard settings are preset by the manufacturer. ${ }^{~}$ The fast settings are set by the application specialist and may vary from surgeon to surgeon.

Abbreviation: SMILE, small incision lenticule extraction. 


\section{Preoperative patient counseling and preparation}

The patient should be adequately counseled, and informed consent should be obtained before starting the procedure. Topical antibiotics may be instilled in both eyes in the pre-operative period. Topical proparacaine $0.5 \%$ is instilled in both eyes to provide topical anesthesia. Excessive instillation of topical anesthesia should be avoided as it may predispose to the formation of black spots and epithelial defects by loosening the corneal epithelium.

\section{Docking}

The patient is placed supine on the operating table with the eye to be operated positioned directly beneath the VisuMax femtosecond laser delivery system, and the patient is asked to fixate on the green internal fixation light. The patient bed is moved up, so that the contact lens "acurvates" the corneal surface. A meniscus tear film appears as soon as the contact lens touches the cornea, and the fixation light becomes clearly visible to the patient as the vergence of the fixation beam is focused according to the patient's refraction. The patient is instructed to look directly in the green light, the centering is checked, and suction is activated. The treatment is centered on the coaxially sighted corneal light reflex (CSCLR), which is the reflection of the blinking green light on the cornea. ${ }^{27}$ Infrared light may be used after activation of suction to confirm the centration of docking. The suction pressure generated by the VisuMax laser system is approximately $35 \mathrm{mmHg}$. Manual compensation for cyclotorsion may be performed after activation of suction in cases with significant astigmatism. ${ }^{28}$

\section{Femtosecond laser application}

The femtosecond laser settings, lenticule, and cap parameters are set as per the surgeon specifications and may be modified as per the case (Tables 2 and 3). Conventionally, the treatment parameters are set at an anterior cap depth of $120 \mu \mathrm{m}$ (range, $100-160 \mu \mathrm{m}$ ) with a side cut width ranging from 2 to $5 \mathrm{~mm}$ and minimum lenticule thickness at edge of $15 \mu \mathrm{m}$ (range, $10-30 \mu \mathrm{m}$ ). A 6.0-mm optical zone is selected with no transition zone for spherical errors and $0.10-\mathrm{mm}$ transition zone for astigmatism. The cap diameter is set to $1 \mathrm{~mm}$ larger than the lenticule diameter. The pulse energy is set between 100 and $160 \mathrm{~nJ}$ and may vary from surgeon to surgeon. ${ }^{27}$

A $500-\mathrm{kHz}$ femtosecond laser is used to create the intrastromal lenticule. The lenticule cut is created first in an outside-in manner, followed by the lenticule side cut and cap cut in an inside-out manner. The cap side cut is created last (Figure 1).
Table 3 Cap and lenticule treatment parameters for small incision lenticule extraction using VisuMax femtosecond laser system

\begin{tabular}{ll}
\hline Treatment parameter & Range \\
\hline Cap parameters & $100-160 \mu \mathrm{m}$ \\
Cap thickness & $6-9.6 \mathrm{~mm}$ \\
Cap diameter & $0^{\circ}-359^{\circ}$ \\
Incision position & $2-5 \mathrm{~mm}$ \\
Incision width & $45^{\circ}-135^{\circ}$ \\
Cap side cut angle & \\
Lenticule parameters & $5-8 \mathrm{~mm}$ \\
Lenticule diameter & $0.10 \mathrm{~mm}$ for CYL \\
Transition zone & 0 for SPH \\
& $10-30 \mu \mathrm{m}$ \\
Minimum lenticule thickness & $90^{\circ}-179^{\circ}$ \\
\hline
\end{tabular}

Abbreviations: CYL, cylindrical; SPH, spherical.

\section{Lenticule dissection}

After femtosecond laser delivery, a uniform bubble layer is observed in the corneal stroma. Two rings are visible corresponding to the diameter of cap cut and lenticule cut, and these rings serve as a visual landmark to identify lenticule edge and guide further dissection (Figure 2). The cap side cut is opened by a thin hooked instrument to its entire depth, and the lenticule edge is identified by delineating anterior and posterior lamellar tunnels at the site of side cut. The anterior and posterior lamellar channels are created in opposite directions to avoid inadvertent lenticule mis-dissection. After identifying the lenticule edge, the anterior lenticule plane is separated from the overlying cap by blunt lamellar dissection. The posterior plane is dissected next, and small peripheral areas are left undissected till the end to provide countertraction during posterior plane dissection and to prevent the lenticule from folding to one side (Figure 3A-E).

\section{Lenticule extraction}

The separated lenticule is extracted via the side-cut incision using a microforceps (Figure 3F). The lenticule should be extracted in a circumferential manner akin to capsulorrhexis to release any residual stromal adhesions and prevent lenticule tears and retained fragments. After extraction, the lenticule must be examined for its completeness. The interface may be irrigated with a balanced salt solution (BSS). The cap is smoothed over the residual stromal bed with the help of merocel sponges or a blunt instrument, and the inbuilt slit-illumination of the VisuMax laser system is used to assess the cap apposition at the end of surgery.

\section{Intraoperative complications}

Various intraoperative complications may be encountered during femtosecond laser application, lenticule dissection, 

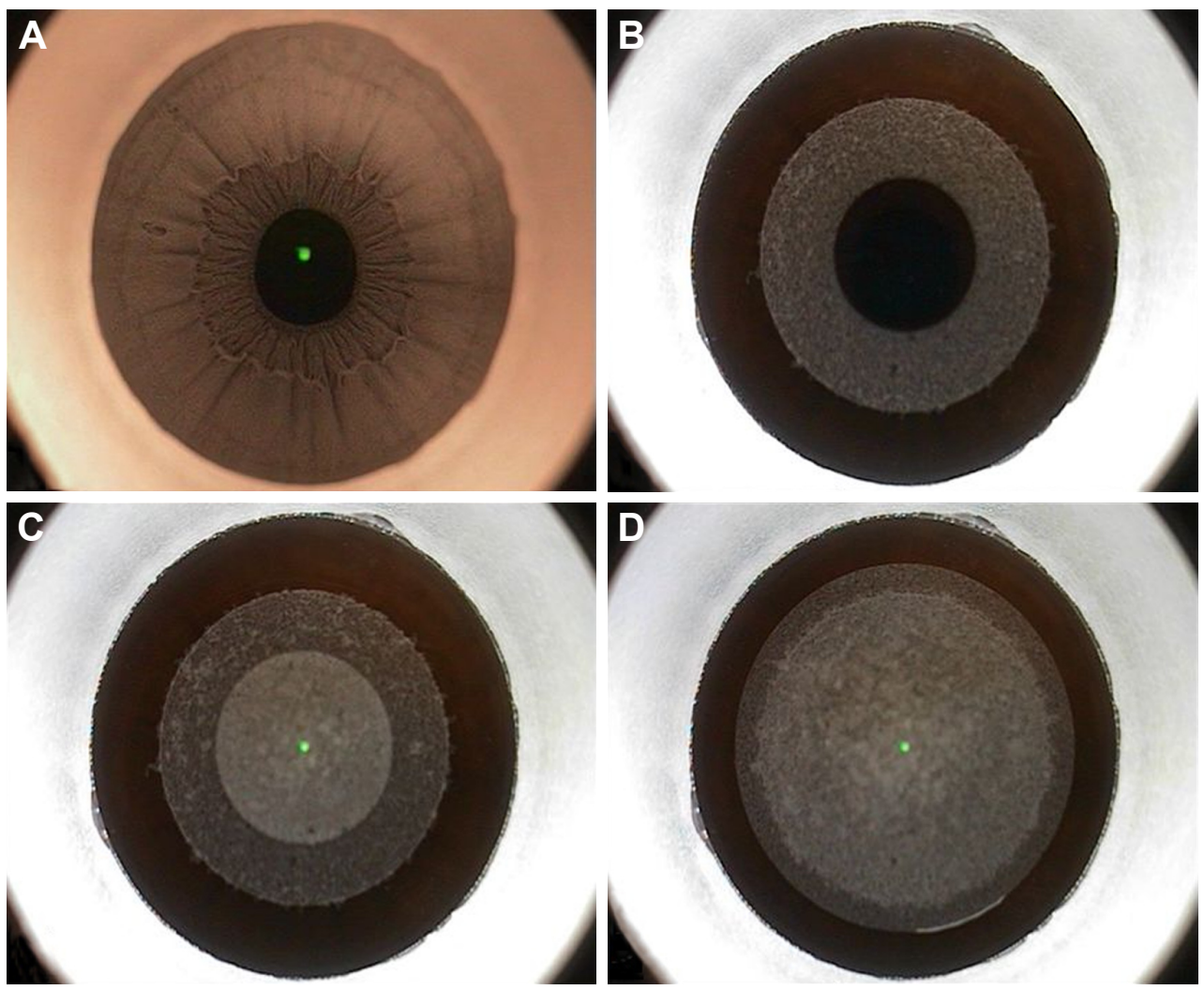

Figure I Femtosecond laser application in small incision lenticule extraction.

Notes: (A) Infrared illumination to confirm centration after docking. (B) Lenticule cut (posterior lamellar plane) created in an outside-in manner. (C) Cap cut (anterior lamellar plane) created in an inside-out manner. (D) Cap side cut created at the final step.

and extraction. Their clinical features, management, and prevention are summarized in Table 4.

\section{Opaque bubble layer (OBL)}

OBL can be observed in cases with too high or too low laser energy settings and results in increased adhesions with difficult dissection. This may lead to delayed visual

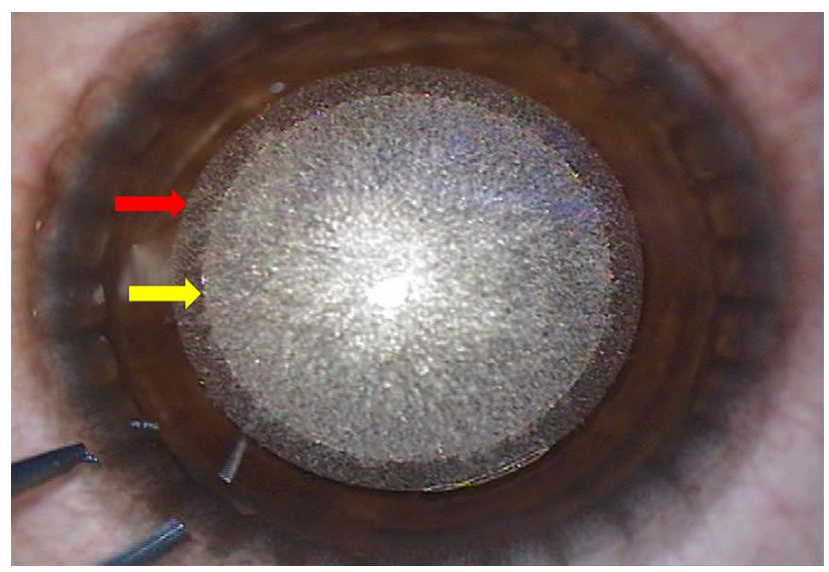

Figure 2 Two concentric rings visible after femtosecond laser application, with the outer ring signifying the cap cut (red arrow) and the inner ring signifying the lenticule cut (yellow arrow). recovery (Figure 4). The area with OBL should be dissected with gentle lamellar movements to release adhesions. ${ }^{11,27}$ Optimal energy settings can help to prevent OBL. Thicker corneas and thinner lenticules predispose to the formation of OBL and should be avoided during the initial learning curve of the surgeon.

\section{Black spots}

Black spots result from inadequate laser delivery in a localized area due to the entrapment of small air bubbles or debris between the applanating surface of the PI and the corneal surface (Figure 5). These black spots cause increased adhesions and difficulty during dissection and may result in delayed visual recovery. ${ }^{11,15,27}$ This may be prevented by adequately wetting the cornea before docking and avoiding any debris on the ocular surface as well as the contact lens. In case debris is noted in the interface after docking, suction should be released and a repeat docking should be attempted after cleaning the PI and irrigating the ocular surface.

\section{Suction loss}

VisuMax femtosecond laser system is a low-pressure system wherein only $35 \mathrm{mmHg}$ of pressure is generated by 

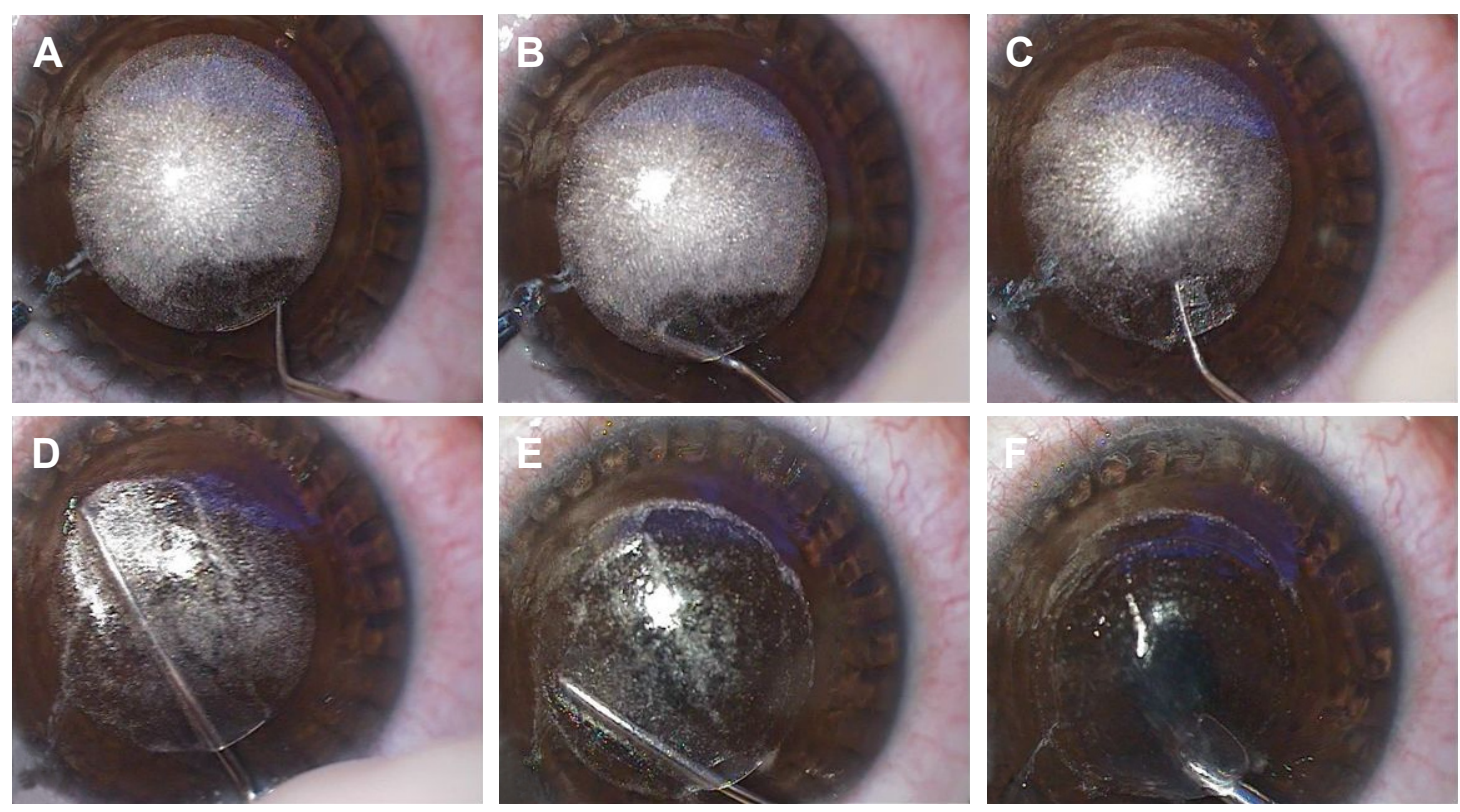

Figure 3 Lenticule dissection and extraction.

Notes: (A) Cap side cut opened with hooked instrument. (B) Anterior lamellar plane delineated on the left-hand side. (C) Posterior lamellar plane delineated on the right-hand side. Meniscus sign confirms the identification of lenticule edge. (D) Anterior plane was dissected first. (E) Posterior plane dissection. (F) Lenticule extracted via microforceps.

Table 4 Intraoperative complications observed during small incision lenticule extraction

\begin{tabular}{|c|c|c|c|c|}
\hline Complication & Pathophysiology & Prevention & Management & Outcomes \\
\hline Suction loss & $\begin{array}{l}\text { Low-suction VisuMax } \\
\text { system with soft docking }\end{array}$ & $\begin{array}{l}\text { Surgeon experience } \\
\text { Avoid difficult orbital } \\
\text { anatomy }\end{array}$ & $\begin{array}{l}\text { Depends on stage of suction } \\
\text { loss - re-dock to complete } \\
\text { procedure or convert to excimer } \\
\text { laser ablation (PRK/LASIK) }\end{array}$ & $\begin{array}{l}\text { Satisfactory visual outcomes in } \\
\text { majority }\end{array}$ \\
\hline Black spots & $\begin{array}{l}\text { Debris/air bubbles } \\
\text { entrapped between } \\
\text { contact lens and cornea }\end{array}$ & & Clean contact lens/ocular surface & $\begin{array}{l}\text { Satisfactory visual outcomes } \\
\text { Increased adhesions during } \\
\text { dissection }\end{array}$ \\
\hline $\mathrm{OBL}$ & $\begin{array}{l}\text { Accumulation and transient } \\
\text { opacification of cavitation } \\
\text { bubbles in intrastromal } \\
\text { interface }\end{array}$ & & $\begin{array}{l}\text { Wait for OBL to disappear/gently } \\
\text { massage out from interface }\end{array}$ & $\begin{array}{l}\text { Delayed visual recovery - eventual } \\
\text { satisfactory visual outcomes } \\
\text { Increased higher order aberrations } \\
\text { and decreased contrast sensitivity }\end{array}$ \\
\hline $\begin{array}{l}\text { Cap lenticular } \\
\text { adhesions }\end{array}$ & $\begin{array}{l}\text { Lenticule mis-dissection - } \\
\text { posterior plane dissected } \\
\text { before anterior plane }\end{array}$ & $\begin{array}{l}\text { Intraoperative signs - } \\
\text { meniscus sign, shimmer } \\
\text { sign, and white ring sign }\end{array}$ & $\begin{array}{l}\text { ASOCT to identify dissection } \\
\text { plane. Sinskey hook-assisted } \\
\text { dissection. Modified strippers } \\
\text { and Y-shaped tip instruments }\end{array}$ & $\begin{array}{l}\text { Increased likelihood of irregular } \\
\text { interface, cap and side-cut tears, } \\
\text { retained lenticule, epithelial defects }\end{array}$ \\
\hline $\begin{array}{l}\text { Retained } \\
\text { lenticule }\end{array}$ & $\begin{array}{l}\text { Difficult lenticule } \\
\text { dissection/forceful } \\
\text { extraction }\end{array}$ & Surgeon experience & $\begin{array}{l}\text { Retreat - surface ablation/LASIK/ } \\
\text { circle pattern of VisuMax laser }\end{array}$ & $\begin{array}{l}\text { Partially retained lenticule } \\
\text { fragments - irregular astigmatism } \\
\text { Completely retained } \\
\text { lenticule - satisfactory visual } \\
\text { outcomes after retreatment }\end{array}$ \\
\hline $\begin{array}{l}\text { Cap tears } \\
\text { Side cut tears }\end{array}$ & $\begin{array}{l}\text { Excessive surgical } \\
\text { manipulation, forceful } \\
\text { lenticule dissection, } \\
\text { and extraction }\end{array}$ & $\begin{array}{l}\text { Avoid rough dissection } \\
\text { and bulky instruments }\end{array}$ & $\begin{array}{l}\text { Frequent instillation of artificial } \\
\text { tears } \\
\text { Bandage contact lens in cap tears } \\
\text { and extensive side-cut tears till } \\
\text { re-epithelialization }\end{array}$ & $\begin{array}{l}\text { Delayed visual recovery } \\
\text { Satisfactory visual outcomes } \\
\text { in majority } \\
\text { Cap tears may lead to stromal } \\
\text { scarring and irregular astigmatism }\end{array}$ \\
\hline $\begin{array}{l}\text { Epithelial } \\
\text { defects }\end{array}$ & $\begin{array}{l}\text { Surgical trauma } \\
\text { Frequent instillation of } \\
\text { topical anesthesia }\end{array}$ & $\begin{array}{l}\text { Avoid frequent instillation } \\
\text { of topical anesthesia } \\
\text { Surgeon experience }\end{array}$ & $\begin{array}{l}\text { Frequent instillation of topical } \\
\text { artificial tears } \\
\text { Bandage contact lens in } \\
\text { large defects }\end{array}$ & $\begin{array}{l}\text { Satisfactory visual } \\
\text { outcomes in majority } \\
\text { Interface haze may occur with } \\
\text { central defects }\end{array}$ \\
\hline
\end{tabular}

Abbreviations: ASOCT, anterior segment optical coherence tomography; LASIK, laser-assisted in situ keratomileusis; OBL, opaque bubble layer; PRK, photorefractive keratectomy. 


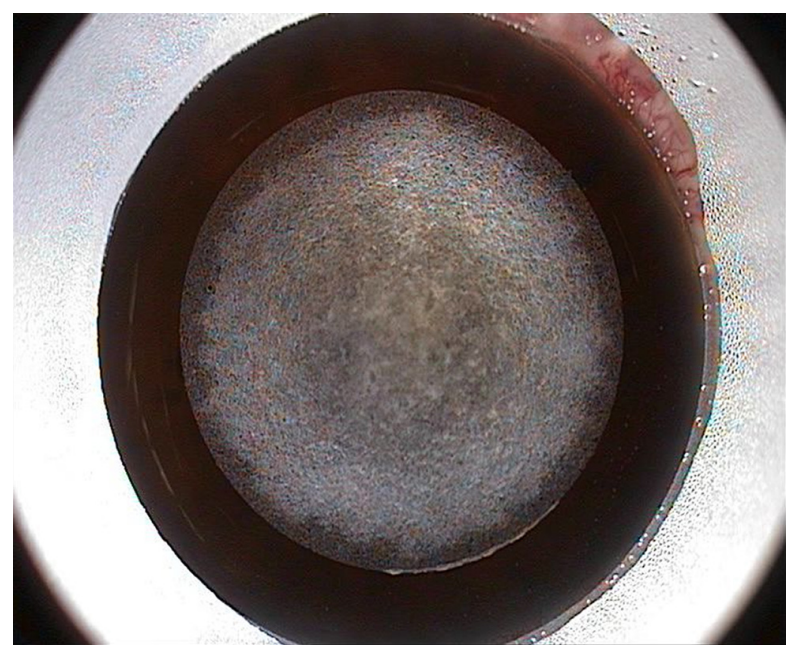

Figure 4 Opaque bubble layer.

the suction cone. The duration of femtosecond laser application is longer (25-28 seconds), which predisposes to suction loss in the presence of associated factors such as improper docking, uncooperative patient, unfavorable orbital anatomy, and inexperienced surgeon (Figure 6).

The management of suction loss depends on the stage at which suction is lost (Table 5). ${ }^{29,30}$ The SMILE procedure may be re-started in the same sitting in cases where suction loss occurs during the initial stages before completion of $10 \%$ of lenticule cut. The VisuMax femtosecond laser machine has an inbuilt repair module that allows the continuation of SMILE procedure after re-docking in cases where the suction is lost during lenticule side cut, cap cut, or cap side cut. It is advisable to clean the contact lens before re-docking, and the procedure should be restarted as soon as possible

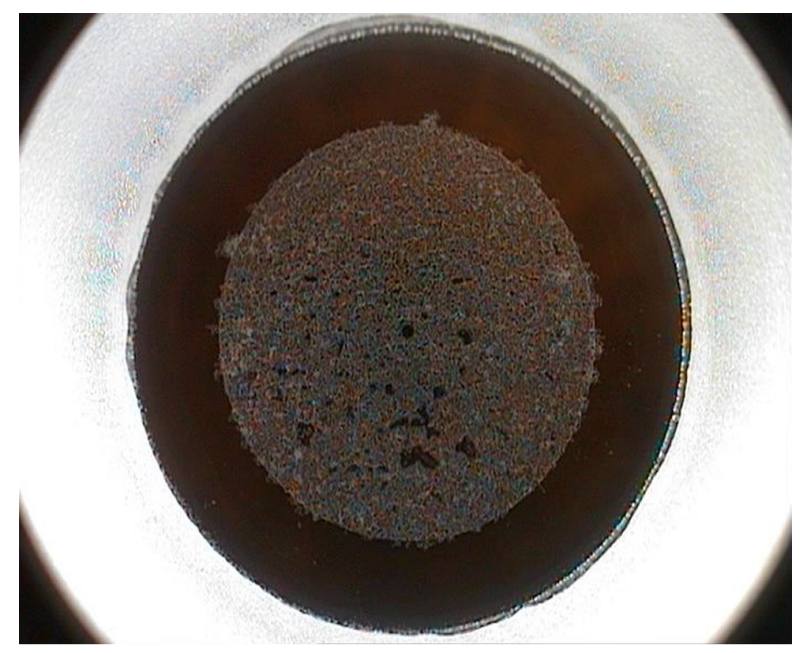

Figure 5 Black spots.

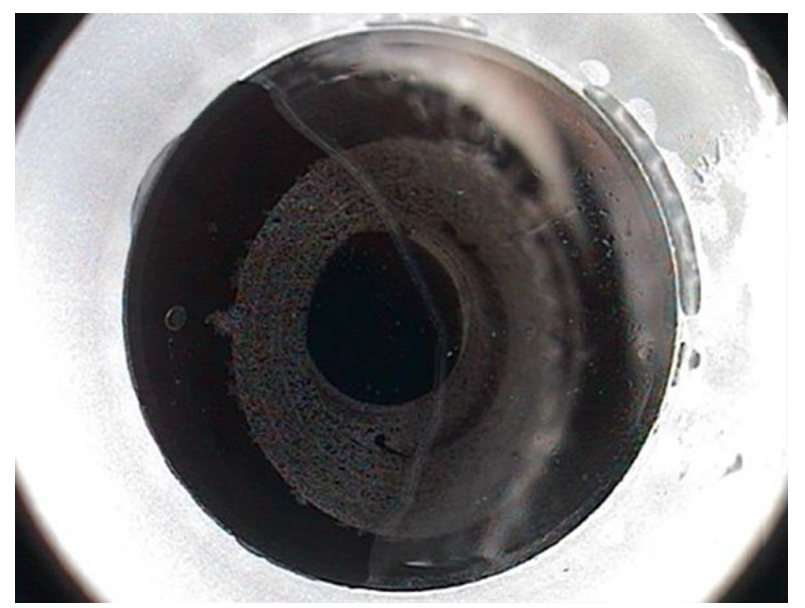

Figure 6 Suction loss during lenticule cut.

before the reference bubble layer disappears. The lenticule diameter and cap diameter may be reduced by $0.2-0.4 \mathrm{~mm}$, and the depth of lenticule side cut may be increased during the repeat procedure to compensate for mild decentration during re-docking.

In cases with suction loss at $>10 \%$ of lenticule cut, the procedure needs to be abandoned, and a re-treatment with LASIK or PRK may be planned in the same sitting or at a later date.

Suction loss may be prevented by checking the machine vacuum tubing preoperatively to ensure optimal functioning. Further, the correct size of the PI should be selected to avoid a mismatch with the patient's cornea. Patient should be counseled to fixate on the green light and avoid ocular or head movements. A self-retaining speculum should be inserted to ensure adequate exposure, any redundant conjunctiva should be swept away from the cornea by merocel sponges, and excessive fluid should be soaked before docking. The presence of a fluid meniscus in the periphery after docking is a sign of imminent suction loss, and the surgeon should

Table 5 Management of intraoperative suction loss based on the stage of suction loss

\begin{tabular}{|c|c|}
\hline Stage of suction loss & Management \\
\hline \multirow[t]{2}{*}{$<10 \%$ lenticule cut } & Re-dock and restart the procedure \\
\hline & $\begin{array}{l}\text { Re-center using infrared light or clear } \\
\text { central bubble }\end{array}$ \\
\hline$>10 \%$ lenticule cut & $\begin{array}{l}\text { Convert to surface ablation/LASIK } \\
\text { (same sitting/later date) }\end{array}$ \\
\hline \multirow[t]{2}{*}{ Lenticule side cut } & Re-dock and repeat from lenticule side cut \\
\hline & Decrease lenticule diameter by $0.2-0.4 \mathrm{~mm}$ \\
\hline Cap cut & Re-dock and repeat from cap cut \\
\hline \multirow[t]{2}{*}{ Cap side cut } & Re-dock and repeat only cap side cut \\
\hline & Decrease cap diameter by $0.2-0.4 \mathrm{~mm}$ \\
\hline
\end{tabular}

Abbreviation: LASIK, laser-assisted in situ keratomileusis. 


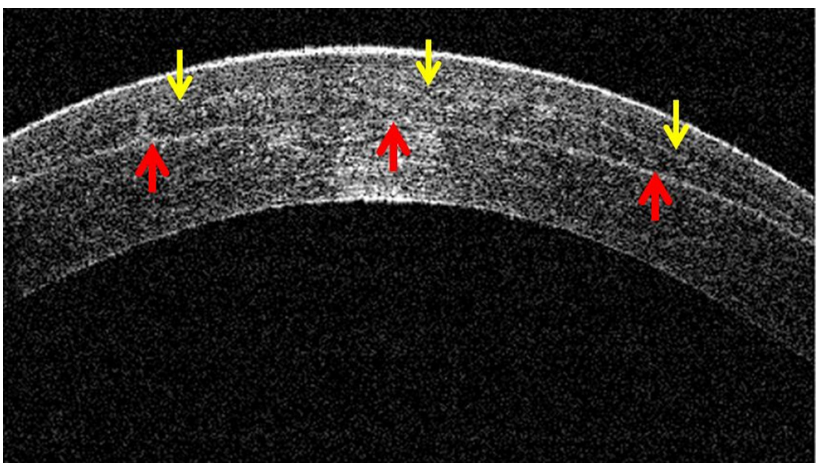

Figure 7 Cap lenticular adhesion with a completely retained lenticule as seen on the anterior segment optical coherence tomography.

Note: The posterior lamellar plane (lenticule cut) is dissected first (red arrows), and the lenticule is stuck to the overlying cap with a faintly visible anterior lamellar plane (yellow arrows).

not start the surgery in this event. It is advisable to release the suction and re-dock in such cases to prevent intraoperative suction loss.

\section{Cap lenticular adhesions}

Cap lenticular adhesion results from an inadvertent dissection of the posterior lenticule plane before separating the anterior lenticule plane from the overlying cap (Figure 7). It is frequently encountered during the initial learning curve of SMILE and leads to subsequent difficult lenticule dissection and extraction. An improper management of cap lenticular adhesion may result in suboptimal visual and anatomical outcomes with an increased incidence of cap tears, side-cut tears, retained lenticule fragments, and iatrogenic damage to corneal stroma. ${ }^{11,14,15}$

Difficult lenticule dissection and extraction is the most common complication encountered during the initial learning curve of SMILE with an incidence of up to $16 \% .{ }^{11}$ Identifying the correct dissection plane can be challenging for novice surgeons, and various intraoperative signs have been described to identify the dissection planes and diagnose as well as prevent cap lenticular adhesions. It may be minimized by avoiding cases with low magnitude of refractive errors as the identification of lenticule edge is more difficult in thin lenticules. Modifications of surgical techniques have been described to successfully extract the lenticule in cases where it is stuck to the overlying cap.

\section{Intraoperative signs to prevent and identify lenticule mis-dissection}

Identifying the lenticule edge at the beginning of surgery is crucial to ensure lamellar separation in the correct plane and prevent lenticule mis-dissection. Meniscus sign, shimmer sign, and white ring sign have been described to aid in the identification of correct dissection plane (Table 6).

\section{Meniscus sign}

Titiyal et $\mathrm{al}^{31}$ describe the "meniscus sign" that provides a landmark to identify the lenticule edge (Figure 8). After femtosecond laser application, a "double ring" is visible signifying the diameter of cap cut (outer ring) and lenticule cut (inner ring). The lenticule edge is identified at the beginning of delineating the anterior and posterior lamellar planes in two different directions. The "meniscus sign" is created by slightly pushing the lenticule edge away from the surgeon during creation of the posterior lamellar channel to create a gap between the inner ring (diameter of lenticule cut) and the lenticule edge. ${ }^{31}$ The lenticule edge assumes a frilled wavy appearance, and the "meniscus sign" is observed as a gap between the lenticule edge and the inner ring.

The meniscus sign is clearly visible during posterior plane dissection but not during anterior plane dissection, and the relation of the frilled lenticule edge with surgical instruments acts as a guide to identify the correct plane of dissection.

Table 6 Intraoperative signs to prevent and identify cap lenticular adhesions

\begin{tabular}{|c|c|c|}
\hline $\begin{array}{l}\text { Intraoperative } \\
\text { sign }\end{array}$ & Description & Application \\
\hline Meniscus sign & $\begin{array}{l}\text { Meniscus-shaped gap between the inner ring (diameter } \\
\text { of lenticule cut) and the lenticule edge created by slightly } \\
\text { pushing the lenticule edge away from the surgeon during } \\
\text { creation of the posterior lamellar channel }\end{array}$ & $\begin{array}{l}\text { Meniscus sign clearly visible during posterior plane dissection } \\
\text { but not during anterior plane dissection } \\
\text { Relation of frilled lenticule edge with surgical instruments acts } \\
\text { as a guide to identify the correct plane of dissection }\end{array}$ \\
\hline Shimmer sign & Bright reflex observed around the dissecting instrument & $\begin{array}{l}\text { Reflex is not visible during dissection of anterior plane and } \\
\text { helps to identify the correct plane of dissection }\end{array}$ \\
\hline White ring sign & $\begin{array}{l}\text { Light reflex from the lenticular side cut, which may be } \\
\text { better observed using oblique external illumination in } \\
\text { darker irides }\end{array}$ & $\begin{array}{l}\text { Position of the white ring relative to the instrument is useful in } \\
\text { identifying the dissection plane, as the white ring is posterior } \\
\text { to the instrument during anterior plane dissection and } \\
\text { anterior to the instrument during posterior plane dissection }\end{array}$ \\
\hline
\end{tabular}




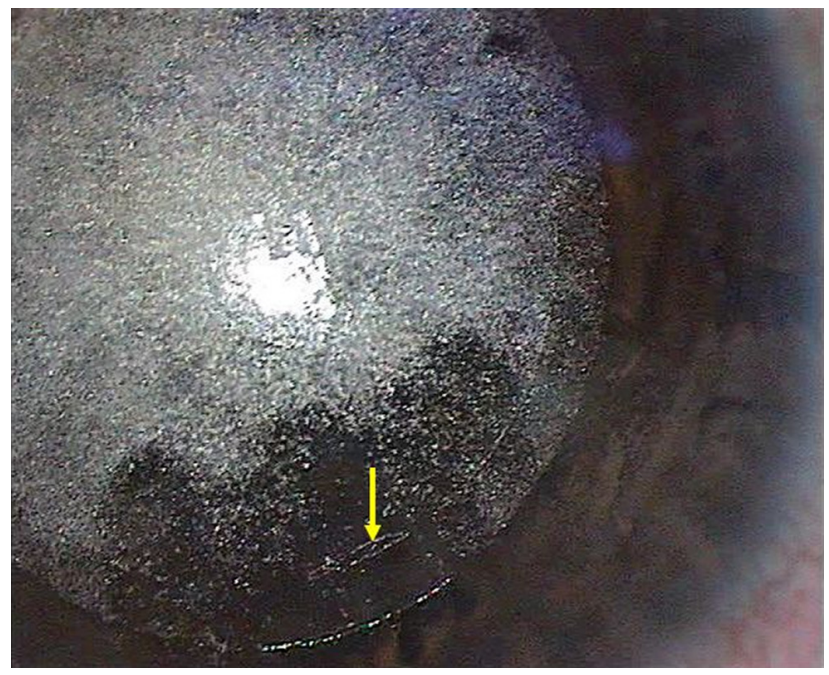

Figure 8 Meniscus sign (yellow arrow).

The advantage of identifying the "meniscus sign" at the beginning of the surgery is a primary prevention of lenticule mis-dissection, rather than identifying cap lenticular adhesion after dissection of posterior plane. No case of cap lenticular adhesion was observed in a series of 50 eyes with this technique, and the lenticule could be completely extracted in all cases.

\section{Shimmer sign}

Shetty et $\mathrm{a}^{32}$ observed a bright reflex or "shimmer sign" around the dissecting instrument in cases with lenticule misdissection wherein the posterior plane is dissected first. This reflex is not visible during dissection of anterior plane and helps to identify the correct plane of dissection.

\section{White ring sign}

Jacob et a ${ }^{33}$ described the "white ring sign", which refers to the light reflex from the lenticular side cut that may be better observed using oblique external illumination in darker irides. The position of the white ring relative to the instrument is useful in identifying the dissection plane, as the white ring is posterior to the instrument during anterior plane dissection and anterior to the instrument during posterior plane dissection. Observing this sign during SMILE can be useful in preventing as well as detecting lenticule mis-dissection.

\section{Surgical techniques to manage cap lenticular adhesions}

In cases with inadvertent cap lenticular adhesions, careful separation of the lenticule from the overlying cap is essential to prevent iatrogenic damage to the lenticule and corneal stroma. The most difficult step in a case with lenticule mis-dissection is identifying the lenticule edge and anterior dissection plane, as the countertraction from the corneal stroma is lost once the posterior plane has been dissected. The techniques described to manage cases of cap lenticular adhesions focus on using various instruments such as Sinskey hook or Y-shaped instruments to facilitate the identification of lenticule edge and to separate it from the overlying cap.

\section{Push-down technique}

Hamed and Fekry ${ }^{34}$ used an instrument with a Y-shaped tip (Bechert Nucleus Rotator, product number E4937, Storz Ophthalmics, Bausch + Lomb, St. Louis, MO, USA) to identify the lenticule edge in case of lenticule mis-dissection. The instrument is inserted through the side-cut incision, and the edge of the lenticule is engaged between the two limbs of the Y-shaped tip. The lenticule is pushed down with the Y-shaped hook, and the instrument is then used to separate the lenticule from the overlying cap.

\section{Anterior segment optical coherence tomography (ASOCT)-guided Sinskey hook-assisted dissection} Identification of lenticule mis-dissection may be difficult for novice surgeons, and Titiyal et $\mathrm{al}^{35}$ advocated the use of ASOCT to diagnose cases of lenticule mis-dissection with retained lenticule (Figure 7). An ASOCT confirms the formation of a complete lenticule and also helps to diagnose cap lenticular adhesion as the plane of dissection is visible posterior to the lenticule. Titiyal et al also used a Sinskey hook to gently separate the edge of the lenticule from the cap. The thin blunt hook helps to lift a small strip of lenticule edge off the anterior cap without the risk of tearing the lenticule. This step helps to identify the anterior plane in a case of cap lenticular adhesion, and the remaining lenticule can be gently peeled off from the overlying cap by a lamellar dissector and microforceps. This technique may be safely used in cases of cap lenticular adhesions and helps to minimize complications that may result from rough lenticule handling.

\section{Retained lenticule}

Partially retained lenticule fragments may be encountered after forceful extraction of an incompletely dissected lenticule. They may be particularly challenging to manage as they lead to irregular astigmatism and visual distortions. The retained lenticules may be extracted in the same sitting with a microforceps after dissecting it from the surrounding stroma. Cap edema may result from prolonged surgical manipulations making visualization of the retained fragments difficult, and it 
may be necessary to defer the procedure of lenticule removal. Prompt removal of lenticule fragments can help restore visual acuity and achieve optimal outcomes. ${ }^{36}$

Customized surface ablation may be attempted in cases where the lenticule fragments cannot be successfully removed; however, the development of postoperative haze may lead to suboptimal visual outcomes. ${ }^{37}$

In cases with completely retained lenticule, the circle pattern of VisuMax laser may be performed, which allows the surgeon to raise a flap and then extract the refractive lenticule similar to FLEx. ${ }^{38,39}$ The circle pattern consists of creating a lamellar ring, a side cut, and a junction cut and converts the original SMILE cap into a complete flap. The lamellar ring is an incision plane encircling the original cap cut. A side cut with a hinge is created around the new incision plane, and the junction cut joins the original cap with the new incision plane to create one larger surface. Alternatively, these cases may be re-treated with corneal ablative procedures.

Forceful lenticule extraction should be avoided to prevent retained lenticule or its fragments. In difficult cases, it is advisable to seek the assistance of more experienced surgeons rather than continue dissection to prevent inadvertent complications.

\section{Cap and side-cut tears}

Cap and side-cut tears may be observed in cases with excessive surgical manipulations due to micro-adhesions or surgical inexperience (Figure 9). The hub of bulky instruments may entangle at the site of side cut and result in extension of side-cut or radial cap tears. A bandage contact lens may be required in addition to frequent lubrication in cases with

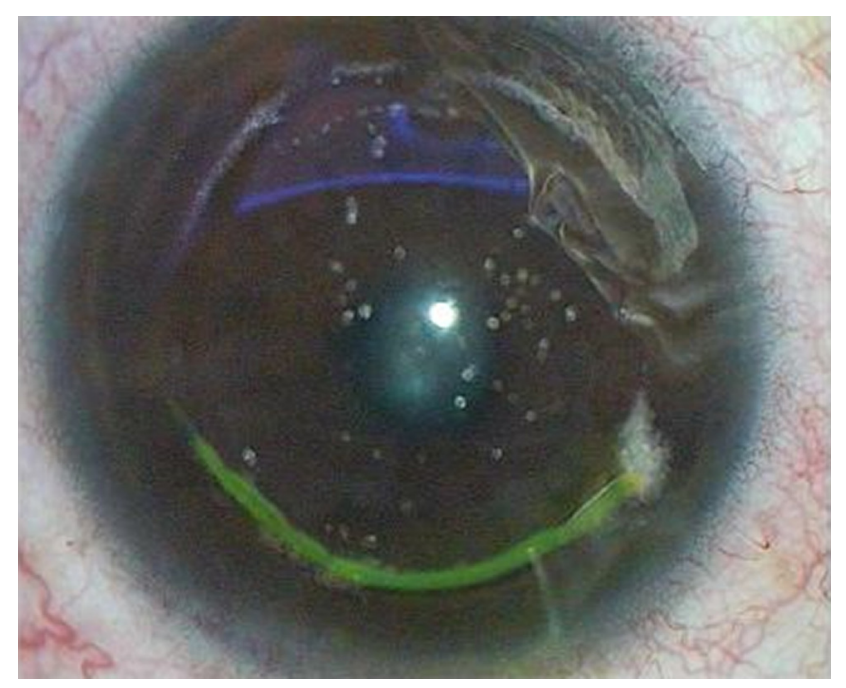

Figure 9 Side-cut tear due to forceful lenticule extraction. radial cap tears or extensive side-cut tears. ${ }^{11}$ These complications may be prevented by using fine caliber instruments and careful dissection to prevent undue distortion of the cap side cut. If the beginnings of a cap tear are noted intraoperatively, surgery should be paused to prevent a radial extension of the tear. Further lenticule dissection and extraction should be performed carefully with smaller gauge instruments if available to prevent an aggravation of the tears. The assistance of a more experienced surgeon may be sought.

\section{Epithelial defects}

Epithelial defects may result from excessive surgical manipulation or frequent instillation of topical anesthesia. Excessive topical anesthesia should be avoided, and precise surgical movements without unnecessary manipulations may help to avoid epithelial defects. Frequent lubrication usually suffices for management although a bandage contact lens may be required in cases with large epithelial defects. ${ }^{11}$

\section{Modifications of surgical techniques of SMILE}

Modifications of the conventional SMILE technique have been described to simplify the surgical technique and decrease the surgical time (Table 7). Laser parameters may be customized by the surgeon to enable smooth dissection with minimal OBL formation.

\section{Modifications of laser parameters}

The VisuMax SMILE laser platform has three modes of treatment, ie, standard, fast, and expert modes. The expert mode has modifiable laser settings, which may be optimized by the surgeon according to the surgeon preference and patient response. The expert mode allows the surgeon to modify energy offset by \pm 6 steps as per the observed clinical effects, in terms of smooth dissection and minimal OBL formation. The laser settings affect the amount of energy being delivered to the cornea, the quality of cut, and the duration of surgery.

A decrease in laser spot distance or track distance results in closer laser spots with a cumulative increase in energy. The cuts may be smoother with less adhesions, but total surgical duration is increased. Widely spaced spots or tracks decrease the duration of laser treatment, but more intraoperative difficulty is experienced owing to increased possibility of adhesions. OBL may be observed with both excessively high energy and low energy. Optimal laser settings help to achieve a uniform smooth bubble layer with minimal adhesions.

Higher pulse energy for cuts is associated with suboptimal visual recovery and increased HOAs. Lower 
Table 7 Modifications of surgical technique of small incision lenticule extraction

\begin{tabular}{|c|c|c|c|}
\hline Technique & Modification & Advantages & Limitation \\
\hline $\begin{array}{l}\text { Chung's swing } \\
\text { technique }^{42}\end{array}$ & $\begin{array}{l}\text { Posterior plane dissected - dissector lifted and swung } \\
\text { at upper margin of lenticule to introduce it in anterior } \\
\text { plane - lenticule cap interface dissected in a fan-shaped } \\
\text { fashion }\end{array}$ & $\begin{array}{l}\text { Simple and fast technique } \\
\text { Significant decrease in the total } \\
\text { surgical duration } \\
\text { Less postoperative pain and } \\
\text { conjunctival injection }\end{array}$ & $\begin{array}{l}\text { Risk of lenticule tears, } \\
\text { edge tears, and cap tears }\end{array}$ \\
\hline $\begin{array}{l}\text { Continuous curvilinear } \\
\text { lenticulerrhexis } \\
\text { technique }^{43}\end{array}$ & $\begin{array}{l}\text { Anterior plane dissected - lenticule grasped with } \\
\text { forceps and extracted in a continuous, circumferential } \\
\text { manner, without separation of the posterior plane }\end{array}$ & $\begin{array}{l}\text { Easy learning curve } \\
\text { Decreased surgical time }\end{array}$ & $\begin{array}{l}\text { Potential risk of lenticule } \\
\text { tear in thin lenticules } \\
\text { Not recommended with } \\
\text { OBL and uneven laser } \\
\text { scanning }\end{array}$ \\
\hline Lenticuloschisis $^{47}$ & $\begin{array}{l}\text { Lenticule is directly peeled off from the surrounding } \\
\text { stroma and extracted with a microforceps without } \\
\text { initial lamellar dissection }\end{array}$ & $\begin{array}{l}\text { Simplified technique } \\
\text { Smoother interface } \\
\text { Better visual quality } \\
\text { Early visual recovery }\end{array}$ & $\begin{array}{l}\text { Lenticule tears may occur } \\
\text { in cases with dense opaque } \\
\text { bubble layer, which leads } \\
\text { to excessive adhesions }\end{array}$ \\
\hline Lenticule irrigation $^{48}$ & $\begin{array}{l}0.2 \mathrm{~mL} \text { of BSS is injected into the small incision after } \\
\text { identifying the anterior and posterior layers of the } \\
\text { lenticule }\end{array}$ & $\begin{array}{l}\text { Minimize corneal epithelial damage } \\
\text { and maintain the stability of the } \\
\text { tear film } \\
\text { Enhanced visual recovery }\end{array}$ & $\begin{array}{l}\text { BSS may introduce } \\
\text { interface debris or hydrate } \\
\text { stroma }\end{array}$ \\
\hline Hydroexpression ${ }^{49}$ & $\begin{array}{l}\text { BSS-assisted expression of the lenticule is performed } \\
\text { after dissecting the lenticule from the surrounding } \\
\text { stroma }\end{array}$ & $\begin{array}{l}\text { Smooth delivery of lenticule with } \\
\text { the minimal use of instruments. } \\
\text { Simple and useful for novice } \\
\text { surgeons. Useful in increased } \\
\text { adhesions and thin lenticules }\end{array}$ & $\begin{array}{l}\text { BSS may introduce } \\
\text { interface debris or hydrate } \\
\text { stroma }\end{array}$ \\
\hline Push-up technique ${ }^{34}$ & $\begin{array}{l}\text { Instrument with a Y-shaped tip used to engage lenticule } \\
\text { edge between the two limbs of the tip and enhance it by } \\
\text { pushing it up from the stromal bed }\end{array}$ & Easy identification of lenticule edge & $\begin{array}{l}\text { Needs specialized } \\
\text { instrument }\end{array}$ \\
\hline $\begin{array}{l}\text { iOCT-assisted } \\
\text { dissection }{ }^{4,50}\end{array}$ & $\begin{array}{l}\text { The dissection planes appear moderately reflective on } \\
\text { iOCT after femtosecond laser delivery and become } \\
\text { hyperreflective after complete dissection. The use of } \\
\text { iOCT can simplify the identification of lenticule edge } \\
\text { and dissection plane }\end{array}$ & $\begin{array}{l}\text { Real-time dynamic visualization } \\
\text { of the surgical process and } \\
\text { instrument-tissue interactions }\end{array}$ & Increased surgical time \\
\hline $\begin{array}{l}\text { Sequential segmental } \\
\text { dissection }^{51}\end{array}$ & $\begin{array}{l}\text { Anterior plane is dissected first followed by the } \\
\text { central part of the posterior plane. Lenticular side cut } \\
\text { (peripheral rim) is dissected at the end in a segmental } \\
\text { and sequential manner }\end{array}$ & $\begin{array}{l}\text { Useful in thin lenticules } \\
\text { Faster }\end{array}$ & $\begin{array}{l}\text { Lenticular mobility may } \\
\text { not allow completion } \\
\text { of dissection of final } \\
\text { segments }\end{array}$ \\
\hline
\end{tabular}

Abbreviations: BSS, balanced salt solution; iOCT, intraoperative optical coherence tomography; OBL, opaque bubble layer.

energy settings are associated with better postoperative uncorrected distance visual acuity. Li et a ${ }^{40}$ observed a spot and track distance of $4.5 \mu \mathrm{m}$ with $125 \mathrm{~nJ}$ energy to provide optimal visual and anatomical results. Conventionally, the cap diameter is $1 \mathrm{~mm}$ larger than the lenticule diameter. Decreasing the cap lenticular diameter difference to $0.4 \mathrm{~mm}$ has been observed to result in superior visual outcomes in the early postoperative period with less induction of HOAs. ${ }^{41}$

\section{Chung's swing technique}

Kim et $\mathrm{a}^{42}$ described a modified method of lenticule separation during SMILE, referred to as the "Chung's swing technique." In contrast to the conventional technique wherein the anterior plane is dissected first, this technique involves the posterior plane dissection first, following which the dissector is introduced in the anterior plane by lifting and swinging the dissector at the upper margin of the lenticule. The lenticule-cap interface is dissected in a fan-shaped fashion. The 12-3 o'clock and 8-11 o'clock positions are not dissected in this method. The separated lenticule is grasped with a McPherson forceps, pushed toward the center, and then pulled to extract it in a clockwise manner. The pushpull maneuver while extracting the lenticule helps to release the residual adhesions.

The authors observed similar efficacy and safety compared to the conventional technique of SMILE. No lenticule tearing or incisional edge tearing was observed with this technique. ${ }^{42}$

This technique is simple and fast and results in a significant decrease in the total surgical duration compared to traditional technique. This may be attributed to the fact that the surgeon does not need to delineate both the anterior and posterior planes of the lenticule edge at the beginning of 
the surgery. The anterior interface of the lenticule is easily identified by lifting and swinging the spatula tip at the left end of the incision after completing separation of the posterior interface. Moreover, since the conjunctiva is not grasped during this technique, relatively fewer patients complained of postoperative pain and conjunctival injection.

The technique has the potential risk of tearing of the lenticule edge, as the 12-3 o'clock and 8-11 o'clock positions are left unseparated during dissection. Separation of the posterior surface before the anterior surface may result in difficult dissection and edge, lenticular, or cap tear.

\section{Continuous curvilinear lenticulerrhexis $(C C L)$ technique}

The CCL technique was first described by Zhao et $\mathrm{al}^{43}$ and involves tearing and extracting the refractive lenticule from the stromal bed in a continuous, circumferential manner, without separation of the posterior plane. After femtosecond laser delivery, the cap-lenticule interface was separated by a spatula introduced through the side-cut incision. The lenticule edge was separated from the stromal bed at the site of side cut; the lenticule was grasped with a microforceps and extracted in a continuous curvilinear clockwise manner. The technique was reported to be safe and efficacious and tended to reduce disturbance to the corneal tissue by instruments. The surgical time was shorter than the conventional technique, and the learning curve was also easier since the dissection of both the anterior and posterior lamellar planes was not required. This technique has also been used to successfully extract the lenticule in a case with cap lenticular adhesions. ${ }^{44}$

Scanning electron microscopy of the extracted lenticule revealed smooth and regular anterior as well as posterior surface of the lenticule. ${ }^{45}$ However, difficult lenticule extraction has been observed in $3.24 \%$ cases with this technique. ${ }^{46}$ There is a potential risk of tearing of the lenticule with this technique, especially in cases with thin refractive lenticules (low myopia) and difficult lenticule extraction. ${ }^{43,46}$ It is not recommended in cases with an OBL, uneven laser scanning, or in any other situation that may increase the difficulty of lenticule extraction. ${ }^{43}$ The surgeon should shift to the conventional method of lenticule extraction in case difficulties are experienced with this technique. ${ }^{46}$

\section{Lenticuloschisis}

Ganesh and Brar $^{47}$ described the technique of lenticuloschisis, wherein the lenticule is directly peeled off from the surrounding stroma and extracted with a microforceps without initial lamellar dissection of the upper and lower lenticule planes. The authors observed a smoother interface as assessed on retroillumination clinical photographs compared to the conventional technique. However, lenticule tears may occur in cases with dense OBL, which leads to excessive adhesions. This technique has been recommended only for surgeons experienced in conventional SMILE technique. Optimized laser energy settings and a minimum peripheral lenticule thickness of 25-30 $\mu \mathrm{m}$ are recommended to achieve optimal outcomes. In addition to simplifying the procedure, the technique may result in early visual recovery and superior visual quality compared to the conventional SMILE technique as there is minimal tissue handling and interface manipulation.

\section{Hydroexpression and lenticule irrigation}

Liu et $\mathrm{al}^{48}$ infiltrated the SMILE interface with BSS to minimize corneal epithelial damage and maintain the stability of the tear film. After femtosecond laser delivery, $0.2 \mathrm{~mL}$ of BSS is injected into the small incision after identifying the anterior and posterior layers of the lenticule. The BSS helped to maintain optical clarity during the surgery, and the lenticule was subsequently dissected and extracted as per the conventional technique. This technique helped to improve the efficacy of SMILE in myopic astigmatism and also enhanced the speed of visual recovery.

$\mathrm{Ng}$ et $\mathrm{al}^{49}$ described the technique of "hydrodissection," wherein a BSS-assisted expression of the lenticule is performed after dissecting the lenticule from the surrounding stroma. After femtosecond laser application, the anterior and posterior planes are separated by blunt dissection from the overlying cap and posterior stroma. A total of $2 \mathrm{~mL}$ of BSS is injected beneath the lenticule via a $27 \mathrm{G}$ irrigation cannula, and the hydrostatic pressure gradient thus created results in a spontaneous expulsion of the lenticule. The technique was observed to be useful in cases with adhesions, as the fluid wave also helped in separating any residual adhesion and allowed for a smooth delivery of lenticule with minimal use of instruments. The step of grasping the lenticule with forceps prior to extracting it is eliminated; thus, this technique may be more simple and useful for novice surgeons. The authors also recommend the use of this technique in cases with low myopia and resultant thin lenticules as it may be difficult to grasp the lenticule edge with forceps in such cases. This modified procedure has similar precision, efficacy, predictability, and safety of refractive correction compared with the conventional technique of SMILE.

\section{Push-up technique}

Hamed and Fekry ${ }^{34}$ describe the push-up technique to facilitate the identification of the lenticule edge. The authors used 
an instrument with a Y-shaped tip (Bechert Nucleus Rotator, product number E4937, Storz Ophthalmics) to engage the lenticule edge between the two limbs of the tip. The lenticule edge is enhanced by pushing it up from the stromal bed with the Y-shaped instrument, and a small linear posterior tunnel is dissected beneath the pushed-up edge to facilitate later dissection of the posterior plane. The anterior lenticule plane is dissected from the overlying cap with a lamellar dissector introduced above the pushed-up edge, followed by the posterior plane dissection through the previously created linear tunnel. The separated lenticule is folded to one side and extracted with the help of microforceps.

\section{Intraoperative optical coherence tomography (iOCT)-assisted dissection}

Microscope-integrated iOCT provides a real-time dynamic visualization of the surgical process and instrument-tissue interactions. A cross-sectional view of the intrastromal lenticule and dissection planes is provided throughout the surgery, and the position of instruments with respect to the lamellar planes can be directly visualized during surgery. The dissection planes appear moderately reflective on iOCT after femtosecond laser delivery and become hyperreflective after complete dissection. ${ }^{44,50}$ The use of iOCT can simplify the identification of lenticule edge and dissection planes for beginners and also help to assess the completion of lenticule removal toward the end of surgery. It can also help to diagnose and manage cases with lenticule mis-dissection and cap lenticular adhesions. At present, iOCT is not integrated in SMILE refractive suite, and the patient needs to be shifted to a separate operation theater with microscope-integrated iOCT. This may lead to a delay of 6 minutes or more and may also compromise the surgical sterility. Moreover, the uniform bubble layer achieved after femtosecond laser delivery may disappear in the interim, making subsequent dissection difficult. ${ }^{50}$

\section{Sequential segmental dissection}

Jacob et $\mathrm{al}^{33,51}$ described the technique of "sequential segmental terminal lenticular side-cut dissection" to facilitate minimally traumatic and smooth lenticular extraction in cases with thin lenticules. After opening the cap side cut, anterior and posterior lamellar cleavage planes are delineated in opposite directions. The anterior plane is dissected first followed by the central part of the posterior plane. The thin band of peripheral rim corresponding to lenticular side cut is left undissected till the end to provide anchorage to the lenticule and prevent its folding upon itself. The lenticular side cut is dissected at the end in a segmental and sequential manner using multiple short sweeps to ensure complete separation of the lenticule from the stromal bed. This facilitates smooth extraction of lenticule with microforceps and avoids complications such as torn and retained lenticule fragments, especially in cases with thin lenticules.

\section{Retreatment and enhancement}

A post-surgical enhancement may be required in $2.7 \%-4 \%$ cases with primary undercorrection, overcorrection, or regression. ${ }^{52,53}$ Moreover, enhancement may also be needed in cases with irregular astigmatism as a result of decentered ablation, difficult lenticule dissection, or partially retained lenticule fragments. Re-treatment is needed in cases with abandoned primary surgical procedure in cases with suction loss or difficult dissection. ${ }^{27}$ The surgical modalities available for or re-treatment include surface ablation, thin-flap LASIK, and the circle pattern of VisuMax laser. A repeat SMILE is not advisable owing to the risk of creating multiple dissection planes; however, the feasibility of sub-cap lenticule extraction is being evaluated in cases that require post-SMILE enhancement.

\section{Future advances}

The applications of SMILE are continuously evolving to include cases with hyperopia, high astigmatism, and at risk for ectasia. ${ }^{54,55}$ The lenticule profile for hyperopia is still evolving and has a large optical and transition zone to reduce the curvature gradient in the region of maximum tissue removal. Collagen cross-linking has been combined with SMILE (SMILE Xtra) to prevent ectasia in high-risk cases with thin corneas and a high magnitude of refractive error. ${ }^{56}$ The refractive lenticule obtained from SMILE is being evaluated in various tissue additive procedures for stromal expansion. ${ }^{57}$ Ultraviolet femtosecond lasers with a shorter wavelength of $345 \mathrm{~nm}$ are being evaluated for corneal flap and intrastromal refractive lenticule creation. They may emerge as a more precise alternative to the conventional infrared femtosecond lasers in the future..$^{58,59}$

\section{Conclusion}

SMILE is increasingly being preferred over conventional flap-based procedures for the treatment of myopia and myopic astigmatism owing to its precision, biomechanical stability, and better ocular surface. Patient selection is essential to achieve optimal visual outcomes and patient satisfaction. Novice surgeons should avoid cases with low magnitude of refractive errors, high astigmatism, difficult orbital anatomy, and uncooperative or anxious patients to minimize intraoperative difficulties. The technique is 
surgically demanding, and various modifications have been described to ease the lenticule dissection and extraction in the initial learning curve. Identification of the lenticule edge and the correct dissection planes are the most crucial steps of surgery. Lenticule mis-dissection is one of the most common complications encountered intraoperatively, and various signs such as meniscus sign, white ring sign, and shimmer sign help to prevent as well as detect cap lenticular adhesions. ASOCT is an important diagnostic modality in cases of lenticule mis-dissection and may help in correct identification of the dissection planes during surgery. As majority of surgeons are still adapting to this surgical procedure, various modifications of the surgical techniques have been described, which may not be universally applicable to all cases. With increasing surgeon experience, a standard technique is expected to evolve that may be performed in all types of cases with optimal outcomes and minimal adverse effects.

\section{Disclosure}

The authors report no conflicts of interest in this work.

\section{References}

1. Sekundo W, Kunert K, Russmann C, et al. First efficacy and safety study of femtosecond lenticule extraction for the correction of myopia: six-month results. J Cataract Refract Surg. 2008;34(9):1513-1520.

2. Sekundo W, Kunert KS, Blum M. Small incision corneal refractive surgery using the small incision lenticule extraction (SMILE) procedure for the correction of myopia and myopic astigmatism: results of a 6 month prospective study. Br J Ophthalmol. 2011;95(3):335-339.

3. Shah R, Shah S, Sengupta S. Results of small incision lenticule extraction: All-in-one femtosecond laser refractive surgery. J Cataract Refract Surg. 2011;37(1):127-137.

4. VisuMax Femtosecond Laser. Small Incision Lenticule Extraction (SMILE) procedure for the correction of myopia: professional use information. Available from: https://www.accessdata.fda.gov/cdrh_docs/ pdf15/P150040D.pdf. Accessed January 6, 2018.

5. Shen Z, Shi K, Yu Y, et al. Small Incision Lenticule Extraction (SMILE) versus Femtosecond Laser-Assisted In Situ Keratomileusis (FS-LASIK) for Myopia: A Systematic Review and Meta-Analysis. PLoS One. 2016;11(7): 0158176.

6. Zhang Y, Shen Q, Jia Y, Zhou D, Zhou J. Clinical Outcomes of SMILE and FS-LASIK Used to Treat Myopia: A Meta-analysis. J Refract Surg. 2016;32(4):256-265.

7. Shen Z, Zhu Y, Song X, Yan J, Yao K. Dry Eye after Small Incision Lenticule Extraction (SMILE) versus Femtosecond Laser-Assisted in Situ Keratomileusis (FS-LASIK) for Myopia: A Meta-Analysis. PLoS One. 2016;11(12):11.

8. Kobashi H, Kamiya K, Shimizu K. Dry Eye After Small Incision Lenticule Extraction and Femtosecond Laser-Assisted LASIK: MetaAnalysis. Cornea. 2017;36(1):85-91.

9. Cai WT, Liu QY, Ren CD, et al. Dry eye and corneal sensitivity after small incision lenticule extraction and femtosecond laser-assisted in situ keratomileusis: a Meta-analysis. Int J Ophthalmol. 2017;10(4): 632-638.

10. Yan H, Gong LY, Huang W, Peng YL. Clinical outcomes of small incision lenticule extraction versus femtosecond laser-assisted LASIK for myopia: a Meta-analysis. Int J Ophthalmol. 2017;10(9):1436-1445.
11. Titiyal JS, Kaur M, Rathi A, et al. Learning Curve of Small Incision Lenticule Extraction: Challenges and Complications. Cornea. 2017; 36(11):1377-1382.

12. Pradhan K, Reinstein D, Carp G, et al. Learning curve for small incision lenticule extraction (SMILE) of a novice corneal laser refractive surgeon evaluated by procedure time for consecutive cases. European Society of Cataract \& Refractive Surgeons. [online] ESCRS website; 2013. Available from: http://escrs.org/amsterdam2013/programme/freepapers-details.asp?id=15825\&day=0. Accessed October 27, 2017.

13. Ang M, Mehta JS, Chan C, et al. Refractive lenticule extraction: transition and comparison of 3 surgical techniques. J Cataract Refract Surg. 2014; 40(9):1415-1424.

14. Ivarsen A, Asp S, Hjortdal J. Safety and complications of more than 1500 small-incision lenticule extraction procedures. Ophthalmology. 2014;121(4):822-828.

15. Ramirez-Miranda A, Ramirez-Luquin T, Navas A, Graue-HernandezEO. Refractive Lenticule Extraction Complications. Cornea. 2015; 34(Suppl 10):S65-S67.

16. Press Announcements $>$ FDA approves VisuMax Femtosecond Laser to surgically treat nearsightedness. Available from: https://www.fda. gov/NewsEvents/Newsroom/PressAnnouncements/ucm520560.htm. Accessed April 19, 2018.

17. Santhiago MR. Percent tissue altered and corneal ectasia. Curr Opin Ophthalmol. 2016;27(4):311-315.

18. Shetty R, Francis M, Shroff R, et al. Corneal Biomechanical Changes and Tissue Remodeling After SMILE and LASIK. Invest Ophthalmol Vis Sci. 2017;58(13):5703-5712.

19. Chen M, Yu M, Dai J. Comparison of biomechanical effects of small incision lenticule extraction and laser-assisted subepithelial keratomileusis. Acta Ophthalmol. 2016;94(7):e586-e591.

20. Mattila JS, Holopainen JM. Bilateral Ectasia After Femtosecond LaserAssisted Small Incision Lenticule Extraction (SMILE). J Refract Surg. 2016;32(7):497-500.

21. El-Naggar MT. Bilateral ectasia after femtosecond laser-assisted smallincision lenticule extraction. J Cataract Refract Surg. 2015;41(4): 884-888.

22. Sachdev G, Sachdev MS, Sachdev R, Gupta H. Unilateral corneal ectasia following small-incision lenticule extraction. J Cataract Refract Surg. 2015;41(9):2014-2018.

23. Wang Y, Cui C, Li Z, et al. Corneal ectasia 6.5 months after small-incision lenticule extraction. $J$ Cataract Refract Surg. 2015;41(5):1100-1106.

24. Gyldenkerne A, Ivarsen A, Hjortdal JØ. Comparison of corneal shape changes and aberrations induced By FS-LASIK and SMILE for myopia. J Refract Surg. 2015;31(4):223-229.

25. Ye MJ, Liu CY, Liao RF, et al. SMILE and Wavefront-Guided LASIK Out-Compete Other Refractive Surgeries in Ameliorating the Induction of High-Order Aberrations in Anterior Corneal Surface. J Ophthalmol. 2016;2016:8702162.

26. Sekundo W, Gertnere J, Bertelmann T, Solomatin I. One-year refractive results, contrast sensitivity, high-order aberrations and complications after myopic small-incision lenticule extraction (ReLEx SMILE). Graefes Arch Clin Exp Ophthalmol. 2014;252(5):837-843.

27. Titiyal JS, Kaur M. Small Incision Lenticule Extraction (SMILE): Surgical Technique and Challenges (Comprehensive Text and Video Guide). 1st ed. New Delhi: Jaypee Brothers; 2018.

28. Ganesh S, Brar S, Pawar A. Results of Intraoperative Manual Cyclotorsion Compensation for Myopic Astigmatism in Patients Undergoing Small Incision Lenticule Extraction (SMILE). J Refract Surg. 2017; 33(8):506-512.

29. Wong CW, Chan C, Tan D, Mehta JS. Incidence and management of suction loss in refractive lenticule extraction. J Cataract Refract Surg. 2014;40(12):2002-2010.

30. Carl Zeiss Meditec AG. FLEx Option. Visante Operation Manual, Germany, Jena: 2011:24-25.

31. Titiyal JS, Kaur M, Brar AS, Falera R. "Meniscus Sign" to Identify the Lenticule Edge in Small-Incision Lenticule Extraction. Cornea. 2018; 37(6):799-801. 
32. Shetty R, Negalur N, Shroff R, Deshpande K, Jayadev C. Cap Lenticular Adhesion During Small Incision Lenticular Extraction Surgery: Causative Factors and Outcomes. Asia Pac J Ophthalmol. 2017; 6(3):233-237.

33. Jacob S, Agarwal A. White Ring Sign and Sequential Segmental Terminal Lenticular Side Cut Dissection for Uneventful and Complete Lenticular Extraction in SMILE. J Refract Surg. 2018;34(2):140-141.

34. Hamed A, Fekry A. Refractive small-incision lenticule extraction: Push-up and push-down techniques. J Cataract Refract Surg. 2016; 42(12):1713-1715.

35. Titiyal JS, Rathi A, Kaur M, Falera R. AS-OCT as a Rescue Tool During Difficult Lenticule Extraction in SMILE. J Refract Surg. 2017; 33(5):352-354.

36. Ganesh S, Brar S, Lazaridis A. Management and Outcomes of Retained Lenticules and Lenticule Fragments Removal After Failed Primary SMILE: A Case Series. J Refract Surg. 2017;33(12):848-853.

37. Ivarsen A, Hjortdal JØ. Topography-guided photorefractive keratectomy for irregular astigmatism after small incision lenticule extraction. J Refract Surg. 2014;30(6):429-432.

38. Riau AK, Ang HP, Lwin NC, et al. Comparison of four different VisuMax circle patterns for flap creation after small incision lenticule extraction. J Refract Surg. 2013;29(4):236-244.

39. Chansue E, Tanehsakdi M, Swasdibutra S, Mcalinden C. Safety and efficacy of VisuMax ${ }^{\circledR}$ circle patterns for flap creation and enhancement following small incision lenticule extraction. Eye Vis. 2015;2:21.

40. Li L, Schallhorn JM, Ma J, Cui T, Wang Y. Energy Setting and Visual Outcomes in SMILE: A Retrospective Cohort Study. J Refract Surg. 2018;34(1):11-16.

41. Torun Acar B, Acar S. Effect of Cap-Lenticule Diameter Difference on the Visual Outcome and Higher-Order Aberrations in SMILE: $0.4 \mathrm{~mm}$ versus 1.0 mm. J Ophthalmol. 2017;2017:8259546-8259547.

42. Kim BK, Mun SJ, Lee DG, Choi HT, Chung YT. Chung's swing technique: a new technique for small-incision lenticule extraction. $B M C$ Ophthalmol. 2016;16(1):154.

43. Zhao Y, Li M, Yao P, et al. Development of the continuous curvilinear lenticulerrhexis technique for small incision lenticule extraction. $J$ Refract Surg. 2015;31(1):16-21.

44. Urkude J, Titiyal JS, Sharma N. Intraoperative Optical Coherence Tomography-Guided Management of Cap-Lenticule Adhesion During SMILE. J Refract Surg. 2017;33(11):783-786.

45. Zhao Y, Li M, Sun L, et al. Lenticule Quality After Continuous Curvilinear Lenticulerrhexis in SMILE Evaluated With Scanning Electron Microscopy. J Refract Surg. 2015;31(11):732-735.

46. Qin B, Zhao J, Zhao Y, et al. Difficulties in lenticule extraction during small incision lenticule extraction with the continuous curvilinear lenticulerrhexis technique. Zhonghua Yan Ke Za Zhi Chin J Ophthalmol. 2016;52:36-40.
47. Ganesh S, Brar S. Lenticuloschisis: A "No Dissection" Technique for Lenticule Extraction in Small Incision Lenticule Extraction. J Refract Surg. 2017;33(8):563-566.

48. Liu T, Zhu X, Chen K, Bai J. Visual outcomes after balanced salt solution infiltration during lenticule separation in small-incision lenticule extraction for myopic astigmatism. Medicine. 2017;96(30):e7409.

49. Ng ALK, Cheng GPM, Woo VCP, Jhanji V, Chan TCY, Alk N, Vcp W. Comparing a new hydroexpression technique with conventional forceps method for SMILE lenticule removal. Br J Ophthalmol. 2017 Epub ahead of print.

50. Sharma N, Urkude J, Chaniyara M, Titiyal JS. Microscope-integrated intraoperative optical coherence tomography-guided small-incision lenticule extraction: New surgical technique. J Cataract Refract Surg. 2017;43(10):1245-1250.

51. Jacob S, Agarwal A, Mazzotta C, Agarwal A, Raj JM. Sequential segmental terminal lenticular side-cut dissection for safe and effective small-incision lenticule extraction in thin lenticules. J Cataract Refract Surg. 2017;43(4):443-448.

52. Liu YC, Rosman M, Mehta JS. Enhancement after Small-Incision Lenticule Extraction: Incidence, Risk Factors, and Outcomes. Ophthalmology. 2017;124(6):813-821.

53. Reinstein DZ, Carp GI, Archer TJ, Gobbe M. Outcomes of small incision lenticule extraction (SMILE) in low myopia. J Refract Surg. 2014; 30(12):812-818.

54. Sekundo W, Reinstein DZ, Blum M. Improved lenticule shape for hyperopic femtosecond lenticule extraction (ReLEx FLEx): a pilot study. Lasers Med Sci. 2016;31(4):659-664.

55. Hansen RS, Lyhne N, Grauslund J, Vestergaard AH. Small-incision lenticule extraction (SMILE): outcomes of 722 eyes treated for myopia and myopic astigmatism. Graefes Arch Clin Exp Ophthalmol. 2016;254(2):399-405.

56. Ganesh S, Brar S. Clinical Outcomes of Small Incision Lenticule Extraction with Accelerated Cross-Linking (ReLEx SMILE Xtra) in Patients with Thin Corneas and Borderline Topography. J Ophthalmol. 2015;2015:1-7.

57. Sun L, Yao P, Li M, et al. The Safety and Predictability of Implanting Autologous Lenticule Obtained by SMILE for Hyperopia. J Refract Surg. 2015;31(6):374-379.

58. Hammer CM, Petsch C, Klenke J, et al. Corneal tissue interactions of a new $345 \mathrm{~nm}$ ultraviolet femtosecond laser. J Cataract Refract Surg. 2015;41(6):1279-1288.

59. Menzel-Severing J, Petsch C, Tourtas T, et al. Evaluation of a $345 \mathrm{~nm}$ Femtosecond Laser for Corneal Surgery with Respect to Intraocular Radiation Hazard. PLoS One. 2015;10(9):e0137638.
Clinical Ophthalmology

\section{Publish your work in this journal}

Clinical Ophthalmology is an international, peer-reviewed journal covering all subspecialties within ophthalmology. Key topics include: Optometry; Visual science; Pharmacology and drug therapy in eye diseases; Basic Sciences; Primary and Secondary eye care; Patient Safety and Quality of Care Improvements. This journal is indexed on Submit your manuscript here: http://www.dovepress.com/clinical-ophthalmology-journal

\section{Dovepress}

PubMed Central and CAS, and is the official journal of The Society of Clinical Ophthalmology (SCO). The manuscript management system is completely online and includes a very quick and fair peer-review system, which is all easy to use. Visit http://www.dovepress.com/ testimonials.php to read real quotes from published authors. 